\title{
Expression profiles and functional prediction of long non-coding RNAs LINC01133, ZEB1-AS1 and $A B H D 11-A S 1$ in the luminal subtype of breast cancer
}

Sepideh Mehrpour Layeghi ${ }^{1 \dagger}$, Maedeh Arabpour ${ }^{1 \dagger}$, Abbas Shakoori $^{2,3}$, Mohammad Mehdi Naghizadeh $^{4}$, Yaser Mansoori ${ }^{4,5}$, Javad Tavakkoly Bazzaz ${ }^{1 *}$ and Rezvan Esmaeili ${ }^{6^{*}}$ (D)

\begin{abstract}
Background: Luminal breast cancer (BC) is the most frequent subtype accounting for more than $70 \%$ of $B C$. LncRNAs, a class of non-coding RNAs with more than 200 nucleotides, are involved in a variety of cellular processes and biological functions. Abberant expression is related to the development of various cancers, such as breast cancer. LINC01133, ZEB1-AS1, and ABHD11-AS1 were reported to be dysregulated in different cancers. However, their expression level in luminal $B C$ remains poorly known. The aim of the present study was to evaluate the potential roles of these IncRNAs in BC, especially in luminal subtypes.

Methods: A comprehensive analysis was performed using the Lnc2Cancer database to identify novel cancer-associated IncRNA candidates. After conducting a literature review, three novel IncRNAs named LINC01133, ZEB1-AS1, and ABHD11-AS1 were chosen as target genes of the present study. Quantitative real-time polymerase chain reaction ( $q R T-P C R$ ) was used to evaluate the expression level of the mentioned IncRNAs in both luminal BC tissues and cell lines. Then, the correlation of the three mentioned IncRNAs expression with clinicopathological characteristics of the patients was studied. Moreover, several datasets were used to discover the potential roles and functions of LINC01133, ZEB1-AS1 and ABHD11-AS1 in luminal subtype of BC.

Results: According to the qRT-PCR assay, the expression levels of LINC01133 and ZEB1-AS1 were decreased in luminal BC tissues and cell lines. On the other hand, ABHD11-AS1 was upregulated in the above-mentioned samples. The expression levels of LINC01133, ZEB1-AS1, and ABHD11-AS1 were not associated with any of the clinical features. Also, the results obtained from the bioinformatics analyses were consistent with qRT-PCR data. Functional annotation of the co-expressed genes with the target IncRNAs, protein-protein interactions and significantly enriched Kyoto Encyclopedia of Genes and Genomes (KEGG) pathways across luminal BC were also obtained using bioinformatics analysis.
\end{abstract}

\footnotetext{
*Correspondence: tavakkolybazzazj@tums.ac.ir; esmaeili.rezvan@gmail.com

†Sepideh Mehrpour Layeghi and Maedeh Arabpour contributed equally to this study

${ }^{1}$ Department of Medical Genetics, School of Medicine, Tehran University of Medical Sciences, Tehran, Iran

${ }^{6}$ Genetics Department, Breast Cancer Research Center, Motamed Cancer Institute, ACECR, Tehran, Iran

Full list of author information is available at the end of the article
}

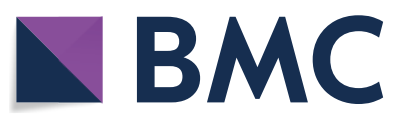

(c) The Author(s) 2021. Open Access This article is licensed under a Creative Commons Attribution 4.0 International License, which permits use, sharing, adaptation, distribution and reproduction in any medium or format, as long as you give appropriate credit to the original author(s) and the source, provide a link to the Creative Commons licence, and indicate if changes were made. The images or other third party material in this article are included in the article's Creative Commons licence, unless indicated otherwise in a credit line to the material. If material is not included in the article's Creative Commons licence and your intended use is not permitted by statutory regulation or exceeds the permitted use, you will need to obtain permission directly from the copyright holder. To view a copy of this licence, visit http://creativecommons.org/licenses/by/4.0/. The Creative Commons Public Domain Dedication waiver (http://creativeco mmons.org/publicdomain/zero/1.0/) applies to the data made available in this article, unless otherwise stated in a credit line to the data. 
Conclusions: Taken together, our findings disclosed the dysregulation of LINC01133, ZEB1-AS1, and ABHD11-AS1 in luminal BC. It was revealed that LINC01133 and ZEB1-AS1 expression was significantly downregulated in luminal BC tissues and cell lines, while ABHD11-AS1 was upregulated considerably in the mentioned tissues and cell lines. Also, bioinformatics and systems biology analyses have helped to identify the possible role of these IncRNAs in luminal BC. However, further analysis is needed to confirm the current findings.

Keywords: Breast cancer, LINC01133, ZEB1-AS1, ABHD11-AS1, Luminal A, Luminal B, Bioinformatics analyses

\section{Introduction}

Breast cancer $(\mathrm{BC})$ is the most common cancer among women worldwide, accounting for $30 \%$ of all female cancers alone $[1,2]$. It is also the second leading cause of cancer death with $11.6 \%$ of the total cancer deaths [3]. The luminal subtype of $\mathrm{BC}$, expressing both estrogen and progesterone receptors $\left(\mathrm{ER}^{+} / \mathrm{PR}^{+}\right)$, accounts for a large percentage of this cancer (more than 70\%) [4,5]. Luminal type of $\mathrm{BC}$ is classified into two groups, luminal $\mathrm{A}$ and luminal $\mathrm{B}$, according to human epidermal growth factor receptor 2 (HER2) status and levels of ki-67 [5]. The leading choice for luminal $\mathrm{BC}$ treatment is endocrine therapy. However, resistance to endocrine therapy is a major challenge for clinicians [6]. Also, similar treatment strategies can provide a variety of responses in luminal subtype patients [7]. In general, despite the better prognosis, due to the heterogeneity and resistance to hormone therapy of luminal subtype, the treatment effectiveness is still limited [7]. Therefore, identifying novel biomarkers and molecular mechanisms of $\mathrm{BC}$ is required to perform early diagnosis and personalized therapeutic strategies. In addition, the limited number of studies on the dysregulation of long non-coding RNAs (lncRNAs) in luminal $\mathrm{BC}$, as well as the high frequency of this subtype, increase the importance of further research on this subgroup.

The GENCODE project results have indicated that only about $2 \%$ of the human genome encodes proteins, whereas the vast majority of it is transcribed into noncoding RNAs [8]. LncRNAs, a class of non-coding RNAs with more than 200 nucleotides, have been shown to play essential roles in many different cellular processes, such as genetic imprinting, transcriptional responses, development, etc. $[9,10]$. Therefore, the aberrant expression of lncRNAs can lead to the pathogenesis of various diseases including cancers [11]. They have been identified as crucial molecules involved in cancer proliferation, invasion, and resistance to therapy $[12,13]$. Some $\operatorname{lncRNAs}$ are expressed highly specific in different cancer types, and some of them are associated with the survival of patients. These two features make them ideal prognostic and diagnostic tools [14]. Due to the development of IncRNAbased therapeutic approaches, determining the role of different lncRNAs in the tumorigenic process is of great importance. Hence, in the present study, we aimed to figure out the expression level and the underlying molecular mechanisms of LINC01133, ZEB1-AS1, and ABHD11AS1 in luminal BC.

LINC01133, a novel lncRNA, is located on chromosome 1q23.2. It was reported that LINC01133 exerted a tumor suppressive role in gastric cancer [15], ovarian cancer [16], and esophageal squamous cell carcinoma [17] progression. It was also found that LINC01133 played oncogenic role in the development of some other cancers [18-20]. These dual roles of LINC01133 could attribute to the tissue-specific expression of this IncRNA. ZEB1-AS1 is associated with the progression and development of several cancers. Its aberrant expression was detected in many tumors [21], such as gastric cancer [22], hepatocellular carcinoma [23], and glioma [24]. ABHD11-AS1, which is located at 7q11.23, is a newly discovered lncRNA. Previous studies have reported the upregulation of this lncRNA in different tumors, including papillary thyroid carcinoma [25] and pancreatic cancer [26]. To the best of our knowledge, the present research is the first study that determines the dysregulation of ABHD11-AS1 in BC so far. Despite all the studies that have been done on these lncRNAs, their biological processes and potential mechanisms, specifically in luminal subtype of $\mathrm{BC}$, are still unclear.

In the present study, we examined the expression level of three lncRNAs in luminal BC by qRT-PCR assay. Furthermore, we performed a correlation analysis between the expression of these lncRNAs and clinicopathological parameters of patients. Finally, to investigate the potential role and mechanism of the lncRNAs in luminal BC, different bioinformatics and systems biology analyses were accomplished using various databases.

\section{Materials and methods Identification of novel IncRNAs and performing literature mining}

Lnc2Cancer database was used to discover novel lncRNAs that are associated with different types of cancers. 
Lnc2Cancer is a comprehensive database which provides lncRNA-cancer correlations between 165 different cancer types and 1614 lncRNAs $[27,28]$. Then, to find lncRNAs that have been less or not studied in breast cancer, a comprehensive PubMed data mining was performed on the candidate lncRNAs. The following keywords were searched: "long non-coding RNA" or "lncRNA", "breast cancer" or "breast carcinoma", and "the candidate lncRNAs". LncRNAs whose expression and role in luminal BC were not studied were selected. Also, among the selected lncRNAs, those that played an important role in several cancer-associated signaling pathways were included in the study.

\section{In-vitro analysis}

\section{Breast cancer tissue samples}

To perform the present case-control study, luminal A and B BC tissue samples and paired adjacent non-cancerous tissues were obtained from 79 patients at Breast Cancer Research Biobank (BCRC-BB) [29]. BCRC-BB follows every ethical guideline about storing and utilizing human biological samples for biobanks. Tissue specimens were snap-frozen in liquid nitrogen and stored at $-80{ }^{\circ} \mathrm{C}$ until performing tests. The inclusion criterion was that patients should not receive any local or systemic treatment before surgery. Clinicopathological parameters including age at diagnosis, tumor size, tumor subtype, grade, stage, pathology of tumors, and ER/PR/HER2 status were retrieved from the hospital records. Written consent was signed by all of the patients, and all the samples were approved by relevant pathologists. Also, the Ethics committee of Tehran University of Medical Sciences (TUMS) approved the present research (Code: IR.TUMS.MEDICINE.REC.1398.792).

\section{Breast cancer cell lines and culture}

Luminal cell lines, MCF7 and T47D, and a non-invasive breast epithelial cell line, MCF10A, were used for the current project. MCF7 and T47D were grown in DMEM (Sigma-Aldrich, St. Louis, MO, USA), 10\% fetal bovine serum (Gibco, Carlsbad, CA, USA), $100 \mathrm{U} / \mathrm{ml}$ penicillin, and $100 \mu \mathrm{g} / \mathrm{ml}$ streptomycin (Sigma-Aldrich, St. Louis, MO, USA). MCF10A were maintained in DMEM supplemented with $5 \%$ fetal bovine serum, epidermal growth factor (EGF) $(20 \mathrm{ng} / \mathrm{ml})$, insulin $(10 \mu \mathrm{g} / \mathrm{ml})$, hydrocortisone $(0.5 \mathrm{mg} / \mathrm{ml})$, cholera toxin $(100 \mathrm{ng} / \mathrm{ml})$, penicillin $(100 \mathrm{U} / \mathrm{ml})$, and streptomycin $(100 \mu \mathrm{g} / \mathrm{ml})$. An incubator at $37{ }^{\circ} \mathrm{C}$ with $5 \% \mathrm{CO}_{2}$ and $95 \%$ humidity was required for maintaining cells.

\section{Isolation of total RNA and qRT-PCR}

Total RNA isolation from breast tissues and cultured cell lines was performed by RiboEx ${ }^{\mathrm{TM}}$ (GeneAll), applying the manufacturer's instructions. Then, complementary DNA (cDNA) synthesis was carried out by performing reverse transcription process of $1 \mu \mathrm{g}$ of isolated RNA samples using $5 \times$ All-In-One RT MasterMix kit (Applied Biological Materials). Next, q-RT PCR was carried out by using AMPLIQON Real Q Plus 2× Master Mix Green Low ROX on LightCycler96 Roche system. Moreover, using serially diluted samples, the efficiencies for each pair of primers of the genes of interest were calculated. The expression levels of the genes of interest were normalized to the expression level of Beta-2-Microglobulin ( $\beta 2 \mathrm{M})$ as an internal control. The primer sequences are listed in Table 1.

\section{Bioinformatics analysis}

Several web servers and databases were used to select the genes of the current study and their role in luminal BC (Table 2).

\section{Gene correlation analysis}

While IncRNAs have constituted a rapidly expanding field of research, only a small number of them has been identified functionally thus far. Analyzing the mechanisms of co-expressed genes with lncRNAs can be very useful in predicting the potential function of novel RNAs. For this purpose, the UCSC Xena Browser [30] was used to select a list of luminal samples. The following parameters were included: "Luminal A", "Luminal B", and "The TCGA Sample ID”. Then, the TCGA ID of the specimens

Table 1 PCR primer sequences

\begin{tabular}{|c|c|c|}
\hline Genes & Forward $\left(5^{\prime}-3^{\prime}\right)$ & Reverse $\left(5^{\prime}-3^{\prime}\right)$ \\
\hline$\beta 2 \mathrm{M}$ & AGATGAGTATGCCTGCCGTG & GCGGCATCTTCAAACCTCCA \\
\hline LINC01133 & GGGGAGAGTAGGTGAAAAGATGA & GCTGGACTTTGGAGAACTTTGC \\
\hline ZEB1-AS1 $(T 5,6)^{\mathrm{a}}$ & TGCATGAAGGTGGTATGGACT & GGGGTAGGAATAGGGATAACTGT \\
\hline ZEB1-AS1(T1-4) ${ }^{\mathrm{a}}$ & CCTGTACCTCCCTGCTAAGC & GCCCAAACTAACTAAACCAGAAAC \\
\hline ABHD11-AS1 & CTCCAGGAACGGGATGAAG & CAGCCTCAGTTTCTCCTCCA \\
\hline
\end{tabular}

B2M Beta-2-Microglobulin, $P C R$ polymerase chain reaction

${ }^{a}$ Two pairs of primers, namely ZEB1-AS1 (T5,6) and ZEB1-AS1(T1-4), were designed to evaluate the expression level of different transcript variants of IncRNA ZEB1-AS1 
Table 2 Bioinformatics tools used to analyze the functions of LINC01133, ZEB1-AS1, and ABHD11-AS1 in BC

\begin{tabular}{lll}
\hline Database & URL & References \\
\hline Lnc2Cancer database & http://www.bio-bigdata.net/Inc2cancer & {$[27,28]$} \\
UCSC Xena & http://xena.ucsc.edu/ & {$[30]$} \\
GDC & https://portal.gdc.cancer.gov & {$[31]$} \\
TANRIC & https://www.tanric.org & {$[32]$} \\
GENEVESTIGATOR & https://genevestigator.com & {$[33]$} \\
ICGC & https://dcc.icgc.org & {$[34]$} \\
DAVID & https://david.ncifcrf.gov & {$[35,36]$} \\
REVIGO & http://revigo.irb.hr & {$[37]$} \\
Cytoscape & http://www.cytoscape.org & {$[38]$} \\
CytoHubba & http://apps.cytoscape.org/apps/cytohubba & {$[39]$} \\
STRING & https://string-db.org & {$[40]$} \\
Enrichr & http://amp.pharm.mssm.edu/Enrichr & {$[41]$} \\
\hline
\end{tabular}

was used to search the FPKM file of the selected samples in the Genomic Data Commons (GDC) database [31]. Finally, a correlation analysis was performed to obtain the co-expressed genes with LINC01133, ZEB1-AS1, and ABHD11-AS1 across the selected samples. Pearson correlation coefficient for the co-expressed genes has been computed by a standard method $(R \geq 0.4)$.

\section{Expression analysis among molecular subtypes of $B R C A$}

The expression pattern of the lncRNAs LINC01133, ZEB1-AS1 and ABHD11-AS1 was further evaluated using TANRIC database [32] across TCGA Breast invasive carcinoma (BRCA) dataset. The analysis was performed among different BC subtypes of the PAM50 classification (Normal-like, Luminal A, Luminal B, Basal and HER2 ${ }^{+}$). TANRIC database has characterized the expression pattern of several lncRNAs using TCGA and different independent datasets (>8000 samples overall). In addition, the expression level of the mentioned lncRNAs was evaluated among luminal and also non-luminal cell lines using GENEVESTIGATOR database [33]. GENEVESTIGATOR integrates thousands of RNA-Seq and microarrays data in order to evaluate gene expression among several cancers.

\section{Oncogenomic analysis}

The International Cancer Genome Consortium (ICGC) portal [34] was used to identify genomic alterations of the selected lncRNAs across luminal BC. The mutational data was obtained from BRCA-EU project including $\mathrm{ER}^{+}$ HER2 ${ }^{-}$tumor subtypes (luminal A and B groups). Also, figures of the lncRNAs were illustrated by trackViewer $R$ Package [42] according to the location of the mutations.

\section{Functional enrichment analysis}

To investigate the associated pathways and functions of LIN01133, ZEB1-AS1 and ABHD11-AS1, functional enrichment analysis of the genes co-expressed with these three lncRNAs was performed using various databases. First, the Database for Annotation, Visualization and Integrated Discovery (DAVID) [35, 36] was used for Gene Ontology (GO) term enrichment analysis. To this end, the list of co-expressed genes with LINC01133, ZEB1AS1 and ABHD11-AS1 was used which was obtained in the previous step. Then, to remove redundant GO terms based on similar measures, the list of GO terms obtained from DAVID was submitted to the REVIGO [37]. At this level, Cytoscape software [38] was utilized for performing a detailed visualization of the networks specified by REViGO. The enrichr database [41] was also used to evaluate pathways in which three lncRNAs may be involved. Calculating and visualizing protein-protein interactions (PPI) of the co-expressed genes with LINC01133, ZEB1AS1 and ABHD11-AS1 were done using the STRING database [40]. Also, the hub genes of the lncRNAs coexpressed genes were explored by the degree method available in CytoHubba [39], a Cytoscape application.

\section{Statistical analysis}

IBM SPSS Statistics (Statistical Package for the Social Sciences, Version 24.0) was used for analyzing the data obtained from the qRT-PCR assay. The tumoral 
and adjacent non-tumoral tissues were extracted from paired sources. The differences between $\Delta \mathrm{Ct}$ values of LINC01133, ZEB1-AS1, and ABHD11-AS1 expression levels in tumor and adjacent non-tumor tissue specimens were analyzed using paired sample t-test. For clinicopathological correlation analysis, the median expression of the lncRNAs was used for dividing 79 patients into two categories: relatively high and relatively low expression of the lncRNAs. Also, correlation analysis of LINC01133, ZEB1-AS1, ABHD11-AS1 and clinicopathological features was carried out by the chi-square and independent t-test. Moreover, Kaplan-Meier method and log-rank test were used to calculate the overall survival rates and compare differences between survival curves, respectively. The data is represented as mean \pm standard deviation (SD). P-values of less than 0.05 were considered significant. The diagnostic value of each gene was calculated via the receiver operating characteristic (ROC) curve analysis. ROC curves were illustrated by IBM SPSS Statistics version 24.0.

\section{Results}

Significantly dysregulated expression of LINC01133, ZEB1-AS1 and ABHD11-AS1 in luminal BC tissues and cell lines

According to the results of the qRT-PCR assay, LINC01133 and ZEB1-AS1 were significantly downregulated in luminal $\mathrm{A}$ and $\mathrm{B} \mathrm{BC}$ tissues $\left(p_{\text {LINC01133 }}=0.001\right)$

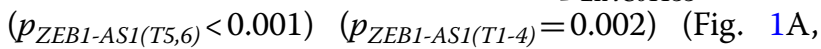
C, E). Also, ABHD11-AS1 expression was upregulated considerably in luminal $\mathrm{BC}$ tissues $(p<0.001$, Fig. $1 \mathrm{G})$. As shown in Fig. 1B, D, F), LINC01133, ZEB1-AS1(T5,6), and ZEB1-AS1(T1-4) were downregulated in $64 \%, 80 \%$ and $71 \%$ of samples, respectively. Moreover, ABHD11AS1 was upregulated in $70 \%$ of cases (Fig. $1 \mathrm{H}$ ).

The results obtained from two luminal $\mathrm{BC}$ cell lines, T47D and MCF7, were consistent with the tissue expression data. The expression of LINC01133 and ZEB1-AS1 was decreased in the mentioned luminal cell lines compared with normal BC cell line (Fig. 2A-C). ABHD11AS1 expression was upregulated significantly in luminal cell lines (Fig. 2D).

\section{Correlation between LINC01133, ZEB1-AS1, and ABHD11-AS1 expression levels and the clinicopathological features}

As shown in Tables 3 and 4, no significant correlation was detected between LINC01133, ZEB1-AS1(T1-4), ZEB1-AS1(T5,6), and ABHD11-AS1 expression with clinicopathological features. Also, according to KaplanMeier analysis, the expression of the lncRNAs was not significantly associated with overall survival of the patients (Additional file 1).

\section{Evaluation of diagnostic value of LINC01133, ZEB1-AS1 and ABHD11-AS1 in luminal BC}

The outcome of ROC analysis was defined based on the type of tissue (tumor or adjacent) and the predictor was characterized as gene expression level (upper or below the median expression). According to the ROC analysis of ZEB1-AS1(T5,6) shown in Fig. 3, the area under ROC curve is 0.729 across luminal $A$ and $B$ subtypes of $B C$ $\left(\mathrm{p}_{\mathrm{ZEB1}-\mathrm{AS1}(\mathrm{T} 5,6)}<0.001\right)$. On the other hand, LINC01133, ZEB1-AS1(T1-4), and ABHD11-AS1 were not suggested as good biomarkers for diagnosis of luminal subtypes of $\mathrm{BC} \quad\left(p_{\text {LINC01133 }}=0.001 / A U C_{\text {LINC01133 }}=0.661\right)\left(p_{\text {ZEBI- }}\right.$ $\left.A S 1(T 1-4)=0.005 / A U C_{Z E B 1-A S 1(T 1-4)}=0.629\right) \quad\left(p_{A B H D 11-}\right.$ $\left.A S 1=0.009 / A U C_{A B H D 11-A S 1}=0.375\right)$.

\section{Expression pattern of IncRNAs LINC01133, ZEB1-AS1 and ABHD11-AS1 among PAM50-breast cancer subtype classifications}

According to the differential expression analysis, lower expression of LINC01133 was observed in luminal A and B BC subtypes. The expression of ZEB1-AS1 in luminal $B$ and HER2 subtypes was lower than other groups. Moreover, significant differences of the expression of these lncRNAs were observed among different PAM50 subtypes $\left(p_{\text {LINC01133 }}=1.13 \mathrm{e}-32\right) \quad\left(p_{\text {ZEB1-AS1 }}=9.82 \mathrm{e}-5\right)$. On the other hand, luminal A and B had higher expression of ABHD11-AS1 followed by Normal-like, HER2, and Basal subtypes. The expression of ABHD11-AS1 was also significantly different among molecular subtypes of $\mathrm{BC}\left(p_{\mathrm{ABHD} 11-\mathrm{AS1}}=2.79 \mathrm{e}-8\right)$ (Additional file 2$)$.

Besides, results obtained from the GENEVESTIGATOR database across luminal $\mathrm{BC}$ cell lines were consistent with the experimental data of the present study which indicated that LINC01133 and ZEB1-AS1 were downregulated in luminal cell lines. Also, expression analysis of these lncRNAs in several non-luminal BC cell lines showed that their expression was also downregulated across these cell lines (Additional files 3, 4). However, as ABHD11-AS1 is a novel lncRNA, no information was available about this lncRNA across GENEVESTIGATOR database. 


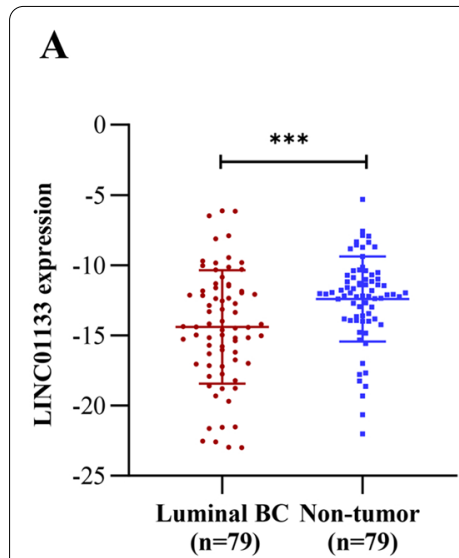

D

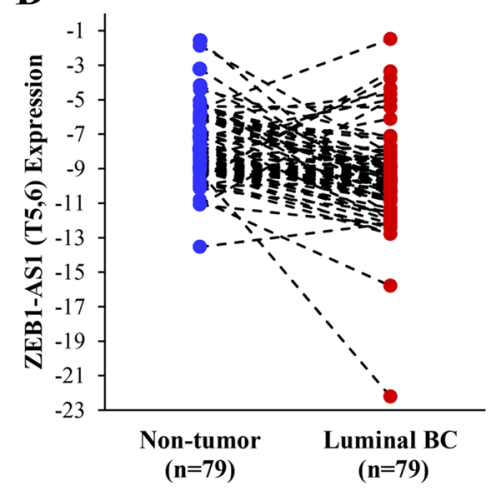

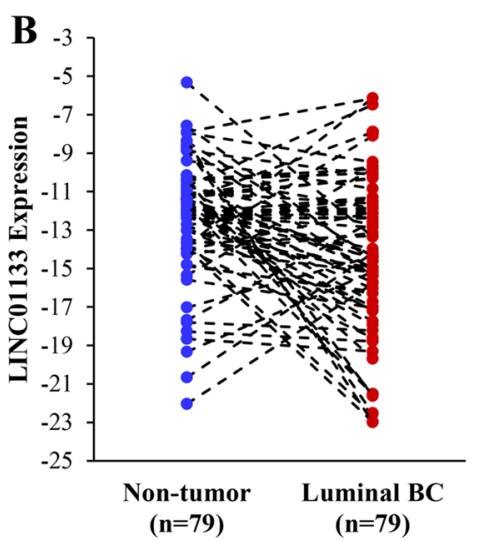

$\mathbf{E}$

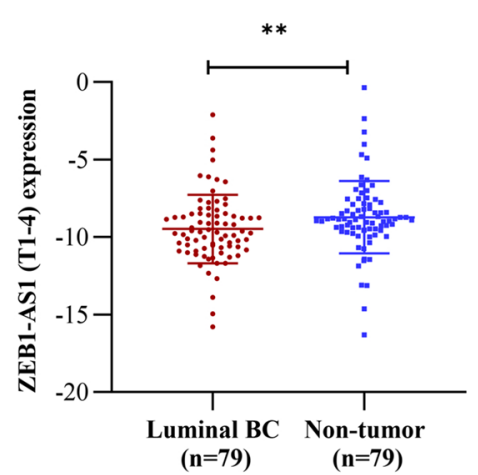

C

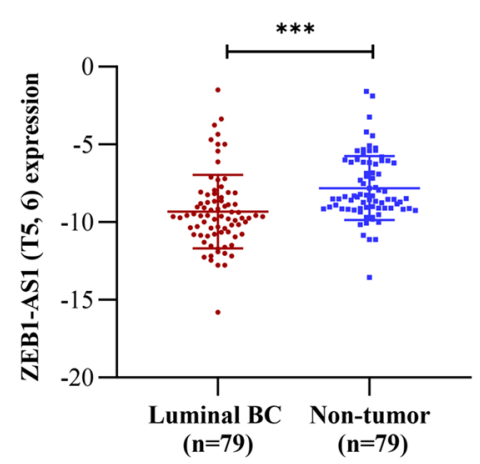

F

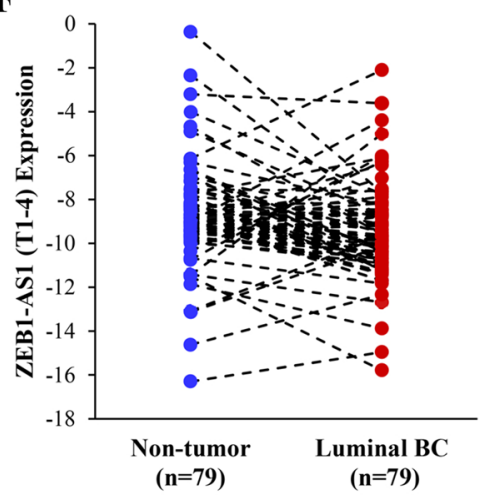

G

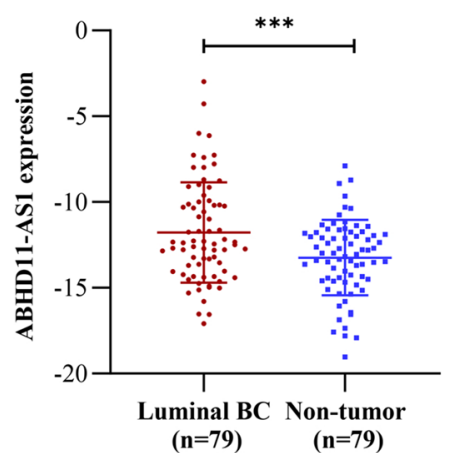

H

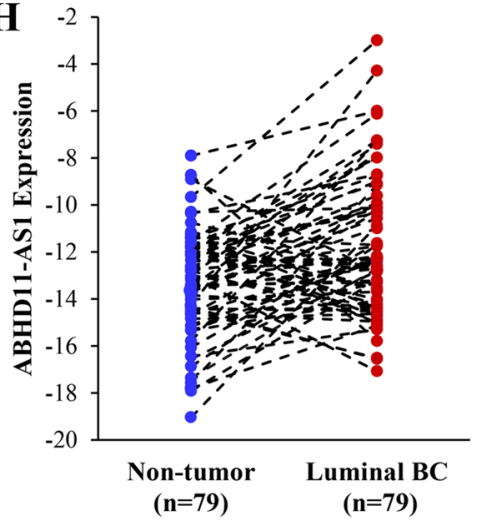

Fig. 1 The expression level of LINC01133, ZEB1-AS1 and ABHD11-AS1 was altered in luminal BC tissues and cell lines compared to adjacent non-tumoral tissues and a normal breast cell line. The IncRNAs expression levels were detected by qRT-PCR in tumoral and non-tumoral tissues from 79 patients. A, B LINC01133 was significantly downregulated in luminal BC tissues (64\% of cases). C, D ZEB1-AS1 (T5,6) was significantly downregulated in luminal BC tissues (80\% of cases). E, F ZEB1-AS1 (T1-4) was significantly downregulated in luminal BC tissues (71\% of cases). G, H ABHD11-AS1 was significantly upregulated in luminal BC tissues (70\% of cases). All PCR reactions were performed three times and compared by paired sample t-test. B2M was used as an internal control. Data was presented as the mean \pm SD. $\left({ }^{* *} p<0.001 ;{ }^{* *} p<0.01\right)$ 

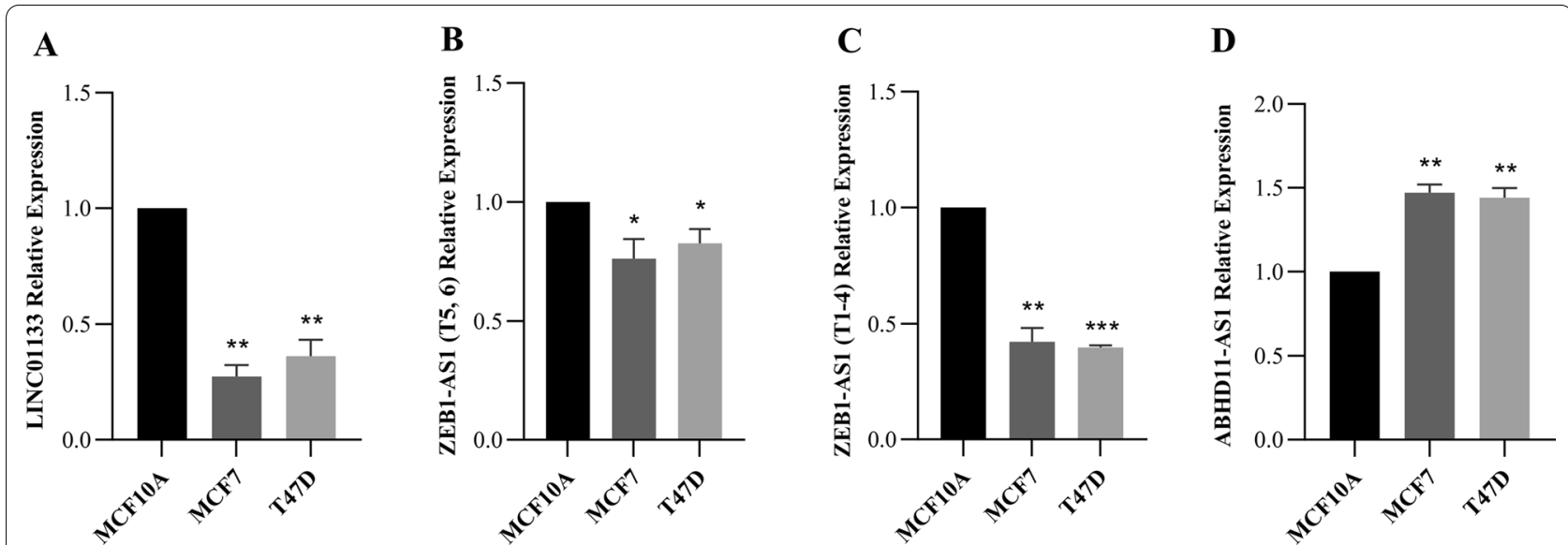

Fig. 2 The expression level of LINC01133, ZEB1-AS1 and ABHD11-AS1 in luminal BC cell lines, T47D and MCF7, compared to a normal breast cell line (MCF10A). A-C LINC01133, ZEB1-AS1 (T5,6) and ZEB1-AS1 (T1-4) was significantly downregulated in luminal BC cell lines. D ABHD11-AS1 was considerably upregulated in luminal cell lines $\left({ }^{* *} p<0.001 ;{ }^{* *} p<0.01 ;{ }^{*} p<0.05\right)$

\section{Genetic alterations of LINC01133, ZEB1-AS1 and ABHD11-AS1 across luminal BC}

According to the results obtained from the ICGC data portal, LINC01133 mutations in $\mathrm{ER}^{+} \mathrm{HER}^{-} \mathrm{BC}$ take place most frequently in intronic, downstream, and upstream regions, respectively. Also, most LINC01133 mutations have been identified to be of the substitution type (Fig. 4A).

It was also found that ZEB1-AS1 mutations occur more frequently on introns and exons and are of the substitution type (Fig. 4B).

Most of ABHD11-AS1 mutations are substitutions which mostly take place in upstream and downstream regions (Fig. 4C).

\section{Co-expression gene network and functional annotation analysis}

A list containing 420 luminal samples (230 luminal A and 190 luminal B) was obtained using UCSC Xena Browser and the Genomic Data Commons (GDC) databases (Additional file 5). Results obtained from the co-expression analysis of LINC01133, ZEB1-AS1, and ABHD11-AS1 across the selected luminal A and B BC samples suggested that these lncRNAs are significantly co-expressed with 256, 149 and 126 genes, respectively $(R \geq 0.4)$ (Additional file 6).

Data retrieved from GO term enrichment analysis by DAVID included a list for categories of biological process $(\mathrm{BP})$, cellular component $(\mathrm{CC})$, and molecular function (MF) (Additional file 7). Also, results of summarizing and excluding redundant $\mathrm{GO}$ terms of the target lncRNAs of the present study, which were performed by REVIGO, were concordant with the data obtained from DAVID GO term enrichment analysis. The top $5 \mathrm{BP}, \mathrm{CC}$, and MF terms related to each lncRNA are shown in Fig. 5. According to it, the genes co-expressed with LINC01133 are significantly involved in biological processes such as ion transport, response to external stimulus, ion transmembrane transport, positive regulation of phosphorylation, etc. It was also determined that molecular function of these genes considerably consists of ion/cation/metal binding, cation transmembrane transporter activity, etc. Each of the above activities takes place inside and/or in the vicinity of a cell. According to $\mathrm{CC}$ terms, it was predicted that the co-expressed genes with LINC01133 are considerably found in extracellular region/exosome, membranebounded vesicle and so on $(p<0.05)$ (Fig. 5A).

It has been found that the co-expressed genes with ZEB1-AS1 are considerably involved in the regulation of RNA metabolic process, regulation of nucleobasecontaining compound metabolic process, nucleic acidtemplated transcription, etc. As shown in Fig. 5B, the most significant molecular functions of these genes are signal transducer activity, kinase activity, phosphotransferase activity, etc. These genes are mostly enriched in the synapse and Golgi lumen $(p<0.05)$.

Moreover, the genes co-expressed with ABHD11-AS1 are considerably involved in biological processes such 
Table 3 Correlation of LINC01133 and ABHD11-AS1 expression with clinicopathological features in luminal BC patients

\begin{tabular}{|c|c|c|c|c|c|c|c|}
\hline \multirow[t]{2}{*}{ Characteristics } & \multirow{2}{*}{$\begin{array}{l}\text { No. of cases } \\
\text { (total: 79) }\end{array}$} & \multicolumn{3}{|c|}{ LINC01133 expression level } & \multicolumn{3}{|c|}{ ABHD11-AS1 expression level } \\
\hline & & $\begin{array}{l}\text { Low } \\
\text { N (\%) }\end{array}$ & $\begin{array}{l}\text { High } \\
\text { N (\%) }\end{array}$ & P-value & $\begin{array}{l}\text { Low } \\
\text { N (\%) }\end{array}$ & $\begin{array}{l}\text { High } \\
\text { N (\%) }\end{array}$ & P-value \\
\hline \multicolumn{8}{|c|}{ Age at diagnosis (2 missing, $n=77$ ) } \\
\hline$\leq 40$ & 20 & $9(25.0 \%)$ & $11(26.8 \%)$ & 0.86 & $7(19.4 \%)$ & $13(31.7 \%)$ & 0.22 \\
\hline$>40$ & 57 & $27(75.0 \%)$ & $30(73.2 \%)$ & & $29(80.6 \%)$ & $28(68.3 \%)$ & \\
\hline \multicolumn{8}{|c|}{ Tumor size (1 missing, $n=78$ ) } \\
\hline$<2 \mathrm{~cm}$ & 23 & $11(29.7 \%)$ & $12(29.3 \%)$ & 0.93 & $9(23.1 \%)$ & $14(35.9 \%)$ & 0.43 \\
\hline $2-5 \mathrm{~cm}$ & 41 & $20(54.1 \%)$ & $21(51.2 \%)$ & & $23(59.0 \%) 18(46.2 \%)$ & & \\
\hline$>5 \mathrm{~cm}$ & 14 & $6(16.2 \%)$ & $8(19.5 \%)$ & & $7(17.9 \%)$ & $7(17.9 \%)$ & \\
\hline \multicolumn{8}{|c|}{ Tumor subtype $(\mathrm{n}=79)$} \\
\hline Luminal A & 65 & $32(80.0 \%)$ & $33(84.6 \%)$ & 0.59 & $34(81.0 \%)$ & $31(83.8 \%)$ & 0.74 \\
\hline Luminal B & 14 & $8(20.0 \%)$ & $6(15.4 \%)$ & & $8(19.0 \%)$ & $6(16.2 \%)$ & \\
\hline \multicolumn{8}{|l|}{ Grade $(n=79)$} \\
\hline 1 & 11 & $7(18 \%)$ & $4(10.0 \%)$ & 0.42 & $5(12.2 \%)$ & $6(15.8 \%)$ & 0.87 \\
\hline 2 & 54 & $24(61.5 \%)$ & $30(75.0 \%)$ & & $29(70.7 \%)$ & $25(65.8 \%)$ & \\
\hline 3 & 14 & $8(20.5 \%)$ & $6(15.0 \%)$ & & $7(17.1 \%)$ & $7(18.4 \%)$ & \\
\hline \multicolumn{8}{|c|}{ Stage ( 2 missing, $n=77$ ) } \\
\hline I & 6 & $2(5.4 \%)$ & $4(10.0 \%)$ & 0.62 & $1(2.4 \%)$ & $5(13.9 \%)$ & 0.16 \\
\hline$\|$ & 42 & $22(59.4 \%) 20$ (50.0\%) & & & $23(56.1 \%)$ & $19(52.8 \%)$ & \\
\hline III & 29 & $13(35.2 \%)$ & $16(40.0 \%)$ & & $17(41.5 \%)$ & $12(33.3 \%)$ & \\
\hline \multicolumn{8}{|c|}{ Pathology of tumors (7 missing, $n=72$ ) } \\
\hline DCIS & 3 & $2(5.9 \%)$ & $1(2.6 \%)$ & 0.80 & $1(3.0 \%)$ & $2(5.1 \%)$ & 0.85 \\
\hline LCIS & 3 & $1(2.9 \%)$ & $2(5.3 \%)$ & & $1(3.0 \%)$ & $2(5.1 \%)$ & \\
\hline IDC & 57 & $28(82.4 \%)$ & $29(76.3 \%)$ & & $28(85.0 \%)$ & $29(74.4 \%)$ & \\
\hline ILC & 4 & $1(2.9 \%)$ & $3(7.9 \%)$ & & $1(3.0 \%)$ & $3(7.7 \%)$ & \\
\hline Others & 5 & $2(5.9 \%)$ & $3(7.9 \%)$ & & $2(6.0 \%)$ & $3(7.7 \%)$ & \\
\hline \multicolumn{8}{|c|}{ Progesterone receptor $(n=79)$} \\
\hline Negative & 10 & $4(10.5 \%)$ & $6(14.6 \%)$ & 0.58 & $4(9.8 \%)$ & $6(15.8 \%)$ & 0.42 \\
\hline Positive & 69 & $34(89.5 \%)$ & $35(85.4 \%)$ & & $37(90.2 \%)$ & $32(84.2 \%)$ & \\
\hline \multicolumn{8}{|c|}{ Estrogen receptor $(n=79)$} \\
\hline Negative & 0 & $0(0.0 \%)$ & $0(0.0 \%)$ & - & $0(0.0 \%)$ & $0(0.0 \%)$ & - \\
\hline Positive & 79 & 38 (100.0\%) 41 (100.0\%) & & & $40(100.0 \%)$ & $39(100.0 \%)$ & \\
\hline \multicolumn{8}{|l|}{ HER2 $(n=79)$} \\
\hline Negative & 70 & $32(86.5 \%)$ & $38(90.5 \%)$ & 0.58 & $37(90.2 \%)$ & $33(86.8 \%)$ & 0.63 \\
\hline Positive & 9 & $5(13.5 \%)$ & $4(9.5 \%)$ & & $4(9.8 \%)$ & $5(13.2 \%)$ & \\
\hline
\end{tabular}

Stage grouping is based on American Joint Committee on Cancer (AJCC). Estrogen receptor (ER), progesterone receptor (PR), and Her2/neu classification is based on IHC results. The positive cut-off point is determined according to IHC guideline of American Society of Clinical Oncology (ASCO)

DCIS Ductal Carcinoma in Situ, LCIS Lobular Carcinoma in Situ, IDC Invasive Ductal Carcinoma, ILC Invasive Lobular Carcinoma

as transmembrane transport, reproductive process, ion transport, neurological system process, etc. They are also considerably involved in various molecular functions including signal transducer activity, transmembrane signaling receptor activity, molecular transducer activity, etc. Additionally, the GO cellular component terms suggested that the co-expressed genes with ABHD11-AS1 are considerably enriched in the intrinsic component of nuclear membrane part, apicolateral plasma membrane, etc. $(p<0.05)$ (Fig. 5C).

The results of gene set enrichment analysis by Enrichr are demonstrated in Fig. 6. According to KEGG, 
Table 4 Correlation of ZEB1-AS1(T1-4) and ZEB1-AS1 (T5,6) expression with clinicopathological features in luminal BC patients

\begin{tabular}{|c|c|c|c|c|c|c|c|}
\hline \multirow[t]{2}{*}{ Characteristics } & \multirow{2}{*}{$\begin{array}{l}\text { No. of cases } \\
\text { (total: 79) }\end{array}$} & \multicolumn{3}{|c|}{ ZEB1-AS1(T1-4) expression level } & \multicolumn{3}{|c|}{ ZEB1-AS1 $(T 5,6)$ expression level } \\
\hline & & $\begin{array}{l}\text { Low } \\
\text { N (\%) }\end{array}$ & $\begin{array}{l}\text { High } \\
\text { N (\%) }\end{array}$ & P-value & $\begin{array}{l}\text { Low } \\
\mathrm{N}(\%)\end{array}$ & $\begin{array}{l}\text { High } \\
\mathrm{N}(\%)\end{array}$ & P-value \\
\hline \multicolumn{8}{|c|}{ Age at diagnosis ( 2 missing, $n=77$ ) } \\
\hline$\leq 40$ & 20 & $12(30.8 \%)$ & $8(21.1 \%)$ & \multirow[t]{2}{*}{0.33} & $12(31.6 \%)$ & $8(20.5 \%)$ & \multirow[t]{2}{*}{0.26} \\
\hline$>40$ & 57 & $27(69.2 \%)$ & $30(78.9 \%)$ & & $26(68.4 \%)$ & $31(79.5 \%)$ & \\
\hline \multicolumn{8}{|c|}{ Tumor size (1 missing, $n=78$ ) } \\
\hline$<2 \mathrm{~cm}$ & 23 & $11(28.9 \%)$ & $12(30.0 \%)$ & \multirow[t]{3}{*}{0.15} & $10(25.7 \%)$ & $13(33.3 \%)$ & \multirow[t]{3}{*}{0.25} \\
\hline $2-5 \mathrm{~cm}$ & 41 & $17(44.8 \%)$ & $24(60.0 \%)$ & & $24(61.5 \%)$ & $17(43.6 \%)$ & \\
\hline$>5 \mathrm{~cm}$ & 14 & $10(26.3 \%)$ & $4(10.0 \%)$ & & $5(12.8 \%)$ & $9(23.1 \%)$ & \\
\hline \multicolumn{8}{|c|}{ Tumor subtype $(n=79)$} \\
\hline Luminal A & 65 & $36(90.0 \%)$ & $29(74.4 \%)$ & \multirow[t]{2}{*}{0.07} & $32(80.0 \%)$ & $33(84.6 \%)$ & \multirow[t]{2}{*}{0.59} \\
\hline Luminal B & 14 & $4(10.0 \%)$ & $10(25.6 \%)$ & & $8(20.0 \%)$ & $6(15.4 \%)$ & \\
\hline \multicolumn{8}{|l|}{ Grade $(n=79)$} \\
\hline 1 & 11 & $6(15.0 \%)$ & $5(12.8 \%)$ & \multirow[t]{3}{*}{0.80} & $6(15.0 \%)$ & $5(12.8 \%)$ & \multirow[t]{3}{*}{0.80} \\
\hline 2 & 54 & $28(70.0 \%)$ & $26(66.7 \%)$ & & $26(65 \%)$ & $28(71.8 \%)$ & \\
\hline 3 & 14 & $6(15.0 \%)$ & $8(20.5 \%)$ & & $8(20.0 \%)$ & $6(15.4 \%)$ & \\
\hline \multicolumn{8}{|c|}{ Stage (2 missing, $n=77$ ) } \\
\hline । & 6 & $3(7.9 \%)$ & $3(7.7 \%)$ & \multirow[t]{3}{*}{0.94} & $3(7.7 \%)$ & $3(7.9 \%)$ & \multirow[t]{3}{*}{0.82} \\
\hline$\|$ & 42 & $20(52.6 \%)$ & $22(56.4 \%)$ & & $20(51.3 \%)$ & $22(57.9 \%)$ & \\
\hline III & 29 & $15(39.5 \%)$ & $14(35.9 \%)$ & & $16(41.0 \%)$ & $13(34.2 \%)$ & \\
\hline \multicolumn{8}{|c|}{ Pathology of tumors (7 missing, $n=72$ ) } \\
\hline DCIS & 3 & $1(2.6 \%)$ & $2(5.9 \%)$ & \multirow[t]{5}{*}{0.20} & $1(2.8 \%)$ & $2(5.6 \%)$ & \multirow[t]{5}{*}{0.32} \\
\hline LCIS & 3 & $3(7.9 \%)$ & $0(0.0 \%)$ & & $0(0.0 \%)$ & $3(8.3 \%)$ & \\
\hline IDC & 57 & $29(76.3 \%)$ & $28(82.4 \%)$ & & $30(83.3 \%)$ & $27(75.0 \%)$ & \\
\hline ILC & 4 & $1(2.6 \%)$ & $3(8.8 \%)$ & & $3(8.3 \%)$ & $1(2.8 \%)$ & \\
\hline Others & 5 & $4(10.6 \%)$ & $1(2.9 \%)$ & & $2(5.6 \%)$ & $3(8.3 \%)$ & \\
\hline \multicolumn{8}{|c|}{ Progesterone receptor $(n=79)$} \\
\hline Negative & 10 & $4(10.0 \%)$ & $6(15.4 \%)$ & \multirow[t]{2}{*}{0.47} & $4(10.0 \%)$ & $6(15.4 \%)$ & \multirow[t]{2}{*}{0.47} \\
\hline Positive & 69 & $36(90.0 \%)$ & $33(84.6 \%)$ & & $36(90.0 \%)$ & $33(84.6 \%)$ & \\
\hline \multicolumn{8}{|c|}{ Estrogen receptor $(n=79)$} \\
\hline Negative & 0 & $0(0.0 \%)$ & $0(0.0 \%)$ & \multirow[t]{2}{*}{-} & $0(0.0 \%)$ & $0(0.0 \%)$ & \multirow[t]{2}{*}{-} \\
\hline Positive & 79 & $40(100.0 \%)$ & $39(100.0 \%)$ & & $40(100.0 \%)$ & $39(100.0 \%)$ & \\
\hline HER2 $(n=79)$ & & & & & & & \\
\hline Negative & 70 & $37(92.5 \%)$ & $33(84.6 \%)$ & 0.69 & $36(90.0 \%)$ & $34(87.2 \%)$ & 0.69 \\
\hline Positive & 9 & $3(7.5 \%)$ & $6(15.4 \%)$ & & $4(10.0 \%)$ & $5(12.8 \%)$ & \\
\hline
\end{tabular}

Stage grouping is based on American Joint Committee on Cancer (AJCC). Estrogen receptor (ER), progesterone receptor (PR), and Her2/neu classification is based on $\mathrm{IHC}$ results. The positive cut-off point is determined according to IHC guideline of American Society of Clinical Oncology (ASCO)

DCIS Ductal Carcinoma in Situ; LCIS Lobular Carcinoma in Situ, IDC Invasive Ductal Carcinoma, ILC Invasive Lobular Carcinoma

Reactome and WikiPathways analysis, the co-expressed genes with LINC01133 are mainly involved in sodium/ proton exchanges, mucin-type O-glycan biosynthesis, and nuclear factor erythroid 2-related factor 2 (NRF2) pathway (Fig. 6A). Moreover, ZEB1-AS1 co-expressed genes are significantly enriched in tight junction interactions, estrogen biosynthesis, glycerophospholipid catabolism, and Wnt signaling pathway across luminal BC (Fig. 6B). The co-expressed genes with ABHD11-AS1 are mainly involved in the processes of Wnt ligand biogenesis, FGFR1 mutant receptor 


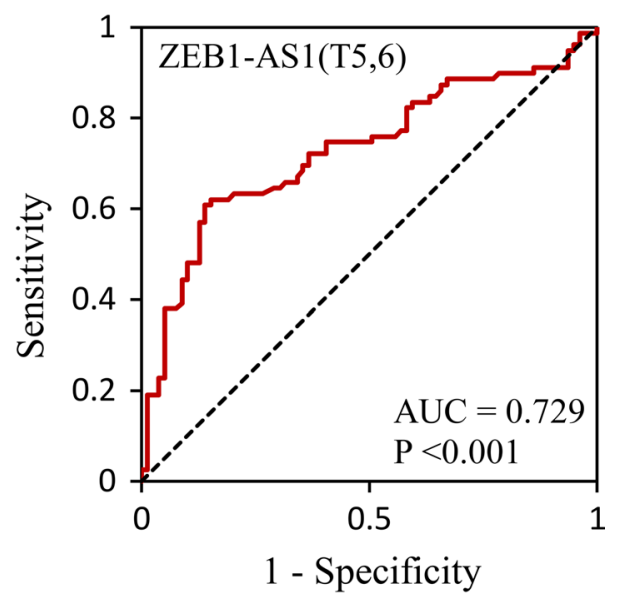

Fig. 3 ROC curve of ZEB1-AS1 $(T 5,6)$ in luminal $B C$. The curve was plotted to examine the diagnostic potential of ZEB1-AS1 $(T 5,6)$ in discriminating luminal $B C$ patients from healthy controls. The area under the curve (AUC) is $0.729(p<0.001)$

activation, mesodermal commitment pathway, and Wnt signaling (Fig. 6C).

Finally, the association analysis of the genes coexpressed with LINC01133 demonstrated that 42 out of 256 genes had a strong PPI (interaction score $>0.4$ ) with each other (Fig. 7A). Also, according to PPI network analysis of the co-expressed genes with ZEB1-AS1 and ABHD11-AS1, 20 and 14 genes have been recognized with strong interactions with each other, respectively (Fig. 7B, C).

According to the CytoHubba, the genes KPRP, PPARG, ST6GALNAC1, and UGT1A1 were adopted as the top hub genes of the PPI network of LINC01133 co-expressed genes ranked by degree metric. Also, five (BAG4, ASH2L, DDHD2, LETM2, and WHSC1L1) and four (LACTB2, SPANXA1, SPANXA2, and SPANXC) genes were adopted as the hob genes related to ZEB1AS1 and ABHD11-AS1 networks, respectively.

\section{Discussion}

The luminal subtype of $\mathrm{BC}$, which has shown better prognosis among the other subtypes, accounts for approximately two-thirds of this cancer [43, 44]. However, it is reported that the luminal B subtype has demonstrated poorer recurrence-free survival in adjuvant treatment categories in comparison to luminal $\mathrm{A}$ [44]. Also, it was proved that a large percentage of $E R^{+}$ patients with lymph node positive benefit less from adjuvant chemotherapy [43]. Due to the heterogeneity of this cancer, the same therapies may demonstrate diverse outcomes in patients. So, distinguishing the underlying mechanisms and specific biomarkers can help the individualized treatment of especially highrisked luminal patients.

In this study, LINC01133 and ZEB1-AS1 were significantly downregulated in luminal $A$ and $B$ BC tissues compared to their adjacent non-tumoral tissues. Also, they were downregulated in luminal cell lines, namely T47D and MCF7, compared to a normal breast cell line (MCF10A). Moreover, ABHD11-AS1 was upregulated considerably in the mentioned tissues and cell lines.

LncRNAs have shown greater expression variability among different individuals and a greater degree of tissue-specificity, compared with coding-genes [45]. The downregulation of LINC01133, ZEB1-AS1(T1-4), and ZEB1-AS1(T5,6) was detected in $64 \%, 71 \%$ and $80 \%$ of patients, respectively. Also, the upregulation of ABHD11-AS1 was found in a large proportion of patients ( $70 \%$ of cases). Song et al. reported that the downregulation of LINC01133 is considerably associated with the poor prognosis of $\mathrm{BC}$ patients [46]. On the other hand, Luo et al. suggested that ZEB1-AS1 promotes triple-negative breast cancer progression [47]. So, this lncRNA may also play an important role in luminal $\mathrm{BC}$ patients, although further investigation is needed. Also, ZEB1-AS1 $(\mathrm{T} 5,6)$ may be used as a biomarker for luminal BC progression. However, more invitro tests are needed for more accurate conclusions.

Limited studies have been performed on the dysregulation of these lncRNAs and their roles in cancers so far. So, the combination of various datasets as well as the analysis of their co-expressed genes could provide better identification of functional roles of the mentioned lncRNAs in luminal BC. According to the result of TCGA data analysis available in TANRIC database, LINC01133, ZEB1-AS1, and ABHD11-AS1 expression were significantly different among PAM50 subtype classification. Besides, the expression pattern of LINC01133 and ZEB1-AS1 across luminal and non-luminal BC cell lines was consistent with the data from TANRIC database and also experimental data of the present study. According to the data obtained from the ICGC data portal, most of the mutations of LINC01133, ZEB1-AS1, and ABHD11AS1 in $\mathrm{ER}^{+} \mathrm{HER}^{-}$patients are from substitution category. The effect of mutations and variations of lncRNAs have not been extensively studied as they constitute a novel class of RNAs. Ponjavic et al. demonstrated that 


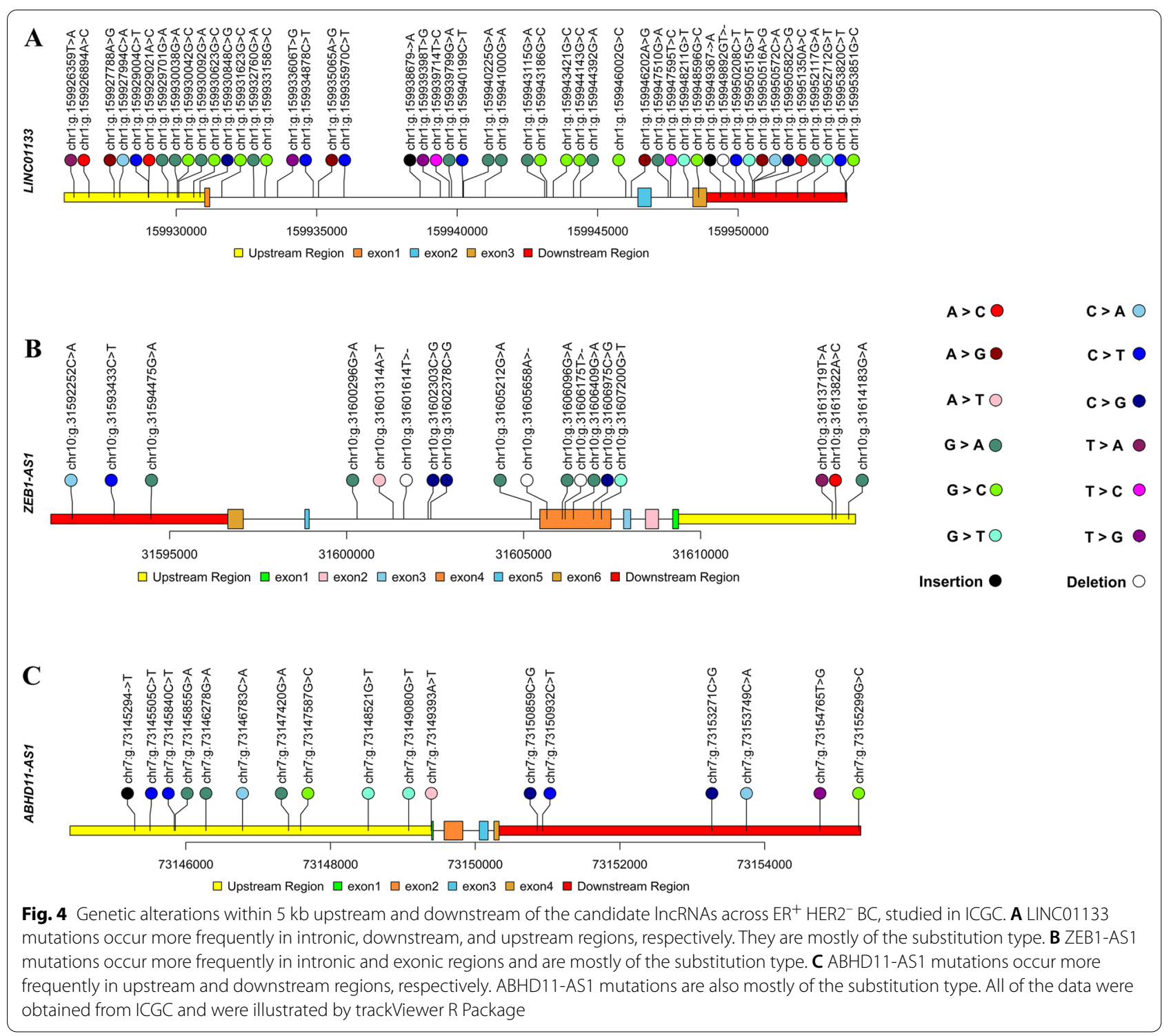

functional lncRNAs show reduced single substitutions, deletions and insertions in their sequences. Although nucleotide substitutions occur mostly in protein-coding sequences compared with noncoding sequences, their effect on lncRNAs are so significant and should not be overlooked [48]. Substitution mutations in lncRNAs may contribute to the pathogenesis of various cancers by disrupting the secondary structure of RNAs $[18,49]$. The RNA secondary structure plays important roles in multiple cellular processes such as gene regulation and localization, splicing, stability and also translation [50]. Also, mutations in the upstream regions of lncRNAs, which constitute a considerable percentage of LINC01133 and ABHD11-AS1 mutations, can have significant effects on them. For example, the presence of single-nucleotide polymorphisms in the promoter of a lncRNA may have an effect on its expression pattern [49]. So, further studies are recommended to determine the effect of these mutations on the structure of the mentioned lncRNAs.

Remarkably, the protein-coding genes are significantly better annotated than lncRNAs [51]. So, in this study, an attempt was made to determine the function of the target lncRNAs with the help of the known functional information of some coding and non-coding genes, using "guiltby-association" principle. According to this principle, 
genes that are involved in some related and/or similar biological pathways may show similar expression patterns across different experimental conditions [52].

According to the "guilt-by-association" principle and the GO term enrichment analysis of the co-expressed genes with LINC01133, this lncRNA might be involved in ion transport, response to external stimulus, and positive regulation of phosphorylation, all of which are cancerassociated biological processes. Also, ion/cation/metal binding and cation transmembrane transporter activity are known as the most crucial molecular functions in which LINC01133 is involved. LINC01133 might be mostly found in extracellular region/exosome and membrane-bounded vesicles.

According to the results obtained from the GO term enrichment analysis of ZEB1-AS1 co-expressed genes, this lncRNA is involved in the regulation of RNA metabolic process, regulation of nucleobase-containing compound metabolic process, nucleic acid-templated transcription, etc. Deregulation of all of these biological processes can lead to the development and progression of various cancers, including BC. In addition, ZEB1AS1 might be plausibly involved in molecular functions including signal transducer activity, kinase activity and phosphotransferase activity, all of which can be linked to cancer progression. ZEB1-AS1 might be mostly enriched in synapse and Golgi lumen.

ABHD11-AS1 might be involved in transmembrane transport, reproductive process, ion transport, neurological system process, etc. ABHD11-AS1 also might be considerably involved in different molecular functions, like signal transducer activity, transmembrane signaling receptor activity, molecular transducer activity, etc. Dysregulation of all of the mentioned functions can lead to the development of various cancers. Moreover, ABHD11AS1 is likely to be found in intrinsic component of nuclear membrane part, apicolateral plasma membrane, etc.

Significantly enriched KEGG, Reactome and WikiPathways of the co-expressed genes with LINC01133 include sodium/proton exchanges, mucin-type O-glycan biosynthesis, and NRF2 pathway. Abnormal glycoprotein structure of tumor cells can affect the survival, growth and metastasis of cancer cells [53]. Nuclear receptors (NR) are known as regulators of physiological processes and play oncogenic or anti-oncogenic roles in cancerous cells [54]. Growing evidence support the involvement of several NRs in the regulation of various pathways related to the initiation and development of $\mathrm{BC}$ [55]. Overexpression of Nrf2 has been shown to increase the expression of glucose-6-phosphate dehydrogenase (G6PD) and Hypoxia-inducing factor $1 \alpha(\mathrm{HIF}-1 \alpha)$ in BC cell lines, including MCF7. Also, overexpression of Nrf2 increases Notch1 expression via the G6PD/HIF-1 $\alpha$ pathway. Notch signaling pathway regulates $\mathrm{BC}$ cell proliferation and migration by affecting the downstream gene, HES-1, and the epithelial-to-mesenchymal transition (EMT) pathway, respectively [56]. All of these evidences suggest that LINC01133 could play an essential role in BC.

Moreover, according to the pathway enrichment analysis, ZEB1-AS1 might be involved in tight junction interactions, estrogen biosynthesis, glycerophospholipid catabolism, and Wnt signaling pathway. All of these pathways can be associated with the progression and development of BC. Steroid hormones increase cell proliferation in $\mathrm{BC}$ [57]. Also, alterations in tight junction complexes could facilitate $\mathrm{BC}$ initiation and progression by impairing their control over crucial cellular processes such as cell motility and polarity [58]. Moreover, the Wnt pathway is significantly activated in breast tumors [59].

ABHD11-AS1 might also be mainly involved in Wnt ligand biogenesis, FGFR1 mutant receptor activation, mesodermal commitment pathway, and Wnt signaling pathway. The involvement of fibroblast growth factors (FGF) has been found in various cellular processes, including proliferation, drug resistance, anti-apoptosis and angiogenesis. Also, amplification of FGFR1 has been found in $\mathrm{ER}^{+} \mathrm{BC}[60]$.

Data from STRING database showed that 42, 20, and 14 co-expressed genes with LINC01133, ZEB1-AS1 and ABHD11-AS1 have strong interactions with each other. These data confirmed the involvement of these lncRNAs and their co-expressed genes in similar biological pathways.

Taken together, the dysregulation of the three potential lncRNAs, LINC01133, ZEB1-AS1, and ABHD11-AS1

\footnotetext{
(See figure on next page.)

Fig. 5 Top 5 gene ontology (GO) terms related to the co-expressed genes with the candidate IncRNAs for categories of biological process (BP), cellular component (CC), and molecular function (MF). A Bar chart of the GO term enrichment analysis of the co-expressed genes with LINC01133. B Bar chart of the GO term enrichment analysis of the co-expressed genes with ZEB1-AS1. C Bar chart of the GO term enrichment analysis of the co-expressed genes with ABHD11-AS1. The top GO terms were selected based on the amount of gene count and the chart was illustrated according to the data obtained from enrichment analysis. The columns were sorted from top to bottom according to significancy of the terms $(p<0.05)$. All of the data was obtained from DAVID database
} 


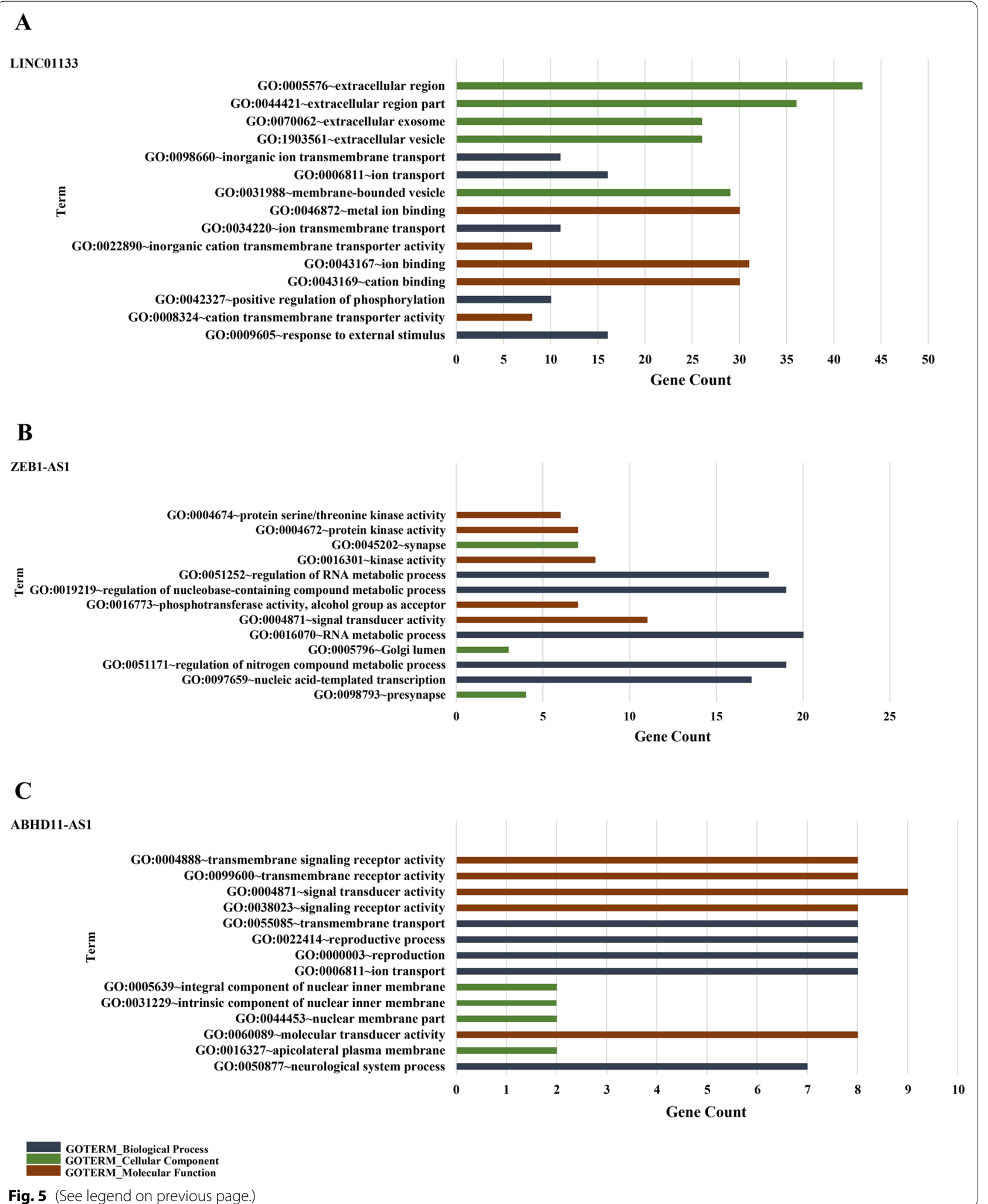




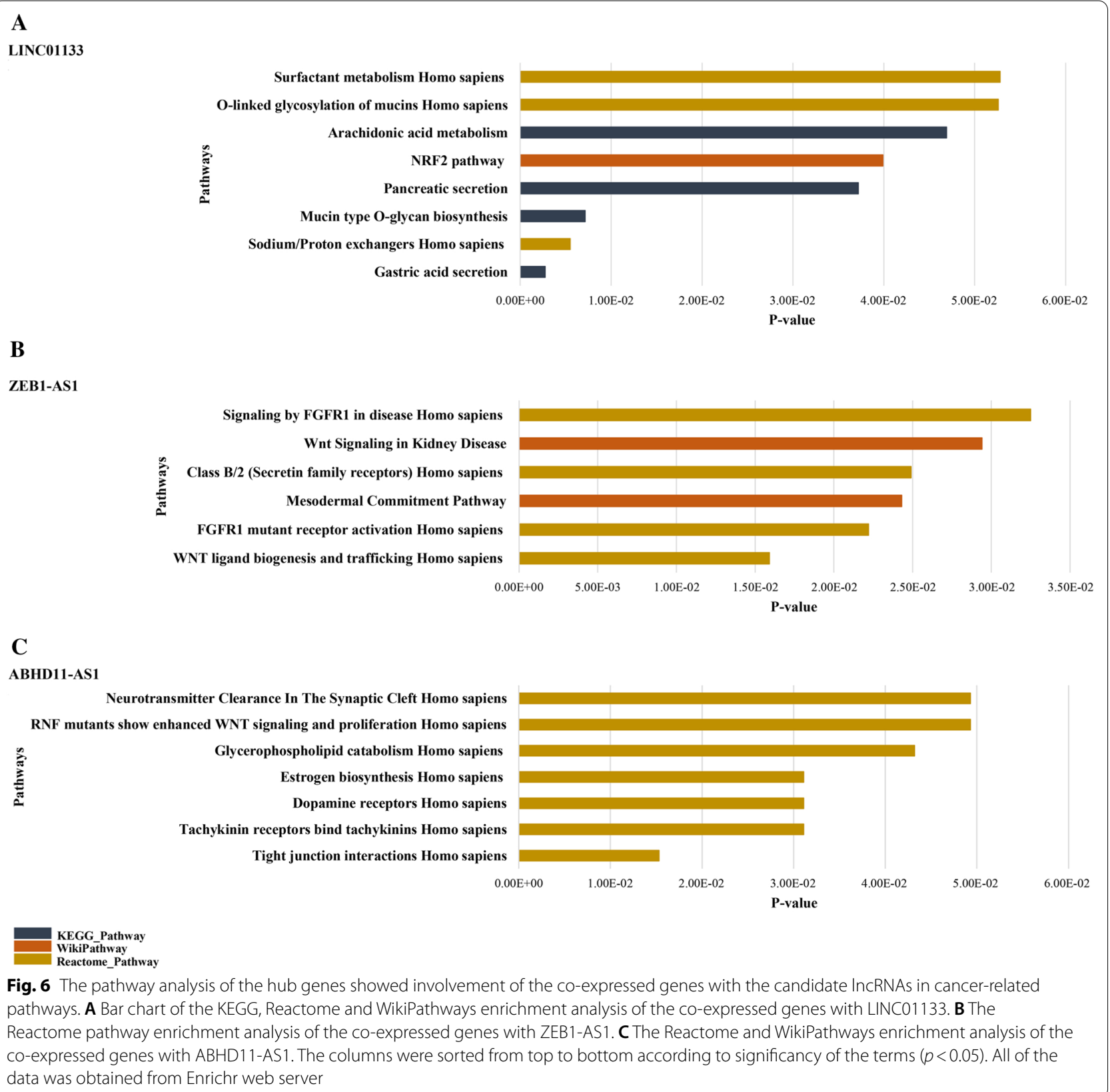

across luminal A and B subtypes of BC was reported in the present study. The bioinformatics analyses performed in this study helped us better identify the possible role of these lncRNAs in luminal BC. However, more experimental studies are needed to confirm these findings and to verify the exact roles of the mentioned lncRNAs.

\section{Conclusions}

All our findings have demonstrated the downregulation of LINC01133 and ZEB1-AS1 across luminal BC tissue specimens and cell lines compared to adjacent non-tumoral tissues and cell line. On the other hand, ABHD11-AS1 was upregulated in the mentioned BC tissues and cell lines. 
A

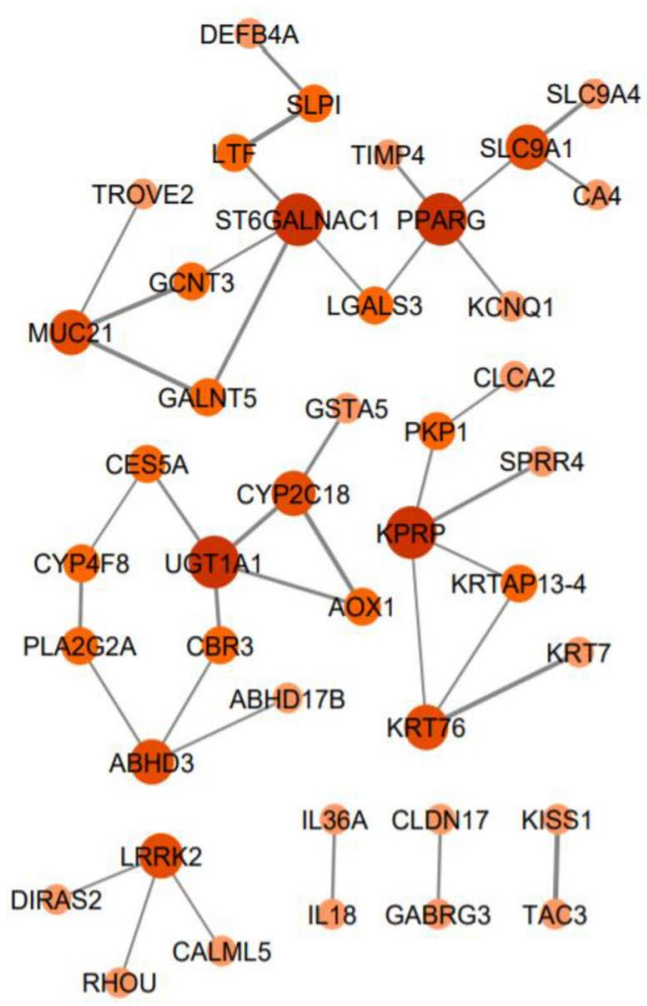

B

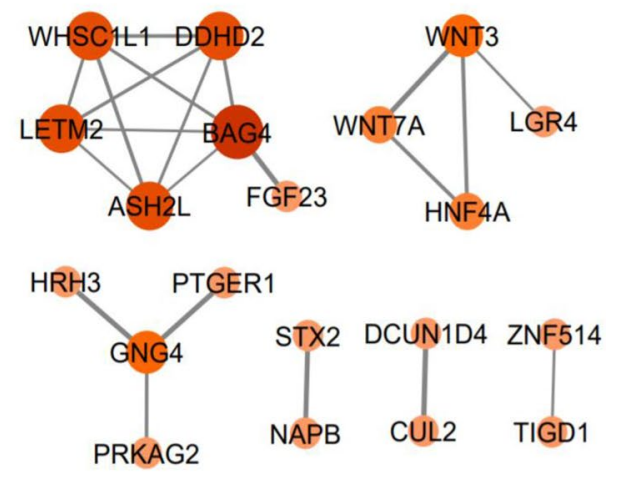

C

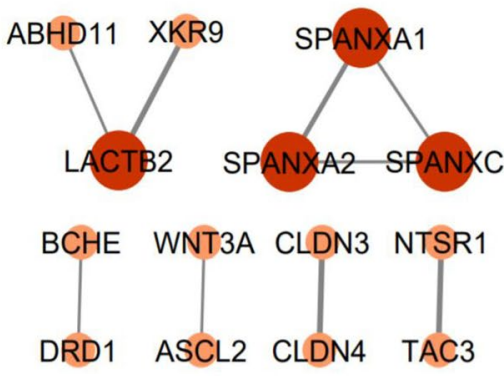

Fig. 7 The analyzed protein-protein networks of the co-expressed genes with the target IncRNAs confirmed strong interactions between a number of genes. A 42 genes co-expressed with LINC01133 have strong interactions with each other. B 20 genes co-expressed with ZEB1-AS1 have strong interactions with each other. C 14 genes co-expressed with ABHD11-AS1 have strong interactions with each other. The thicker edge and the stronger node color are representative of the higher STRING combined-score and the higher degree, respectively. Data was obtained from the STRING database and was illustrated by Cytoscape (interaction score $>0.4$ )

\section{Abbreviations}

BC: Breast cancer; LncRNAs: Long non-coding RNAs; QRT-PCR: Quantitative real-time polymerase chain reaction; KEGG: Kyoto Encyclopedia of Genes and Genomes; ER: Estrogen receptor; PR: Progesterone receptor; HER2: Human epidermal growth factor receptor 2; BCRC-BB: Breast Cancer Research Biobank; TUMS: Tehran University of Medical Sciences; EGF: Epidermal growth factor; CDNA: Complementary DNA; $\beta 2 \mathrm{M}$ : Beta-2-Microglobulin; PCR: Polymerase chain reaction; GDC: Genomic Data Commons; BRCA: Breast invasive carcinoma; ICGC: The International Cancer Genome Consortium; DAVID: The Database for Annotation, Visualization and Integrated Discovery; GO: Gene ontology; PPI: Protein-protein interaction; IBM SPSS Statistics: Statistical Package for the Social Sciences; SD: Standard deviation; ROC: Receiver operating characteristics; ICGC: The International Cancer Genome Consortium; BP: Biological process; CC: Cellular component; MF: Molecular function; NRF2: Nuclear factor erythroid 2-related factor 2; NR: Nuclear receptors; G6PD: Glucose-6-phosphate dehydrogenase; EMT: Epithelial-to-mesenchymal transition; HIF-1a: Hypoxia-inducing factor 1a; FGF: Fibroblast growth factors.

\section{Supplementary Information}

The online version contains supplementary material available at https://doi. org/10.1186/s12967-021-03026-7.

Additional file 1. Figure S1. The kaplan-meier survival functions of LINC01133, ZEB1-AS1(T1-4), ZEB1-AS1(T5,6), and ABHD11-AS1 across luminal BC samples.
Additional file 2. Figure S2. Differential expression of LINC01133, ZEB1AS1 and ABHD11-AS1 across different subtypes of BC, obtained by TANRIC database.

Additional file 3. Figure S3. The expression level of LINC01133 across various $B C$ cell lines, obtained by GENEVESTIGATOR database.

Additional file 4. Figure S4. The expression level of ZEB1-AS1 across various BC cell lines, obtained by GENEVESTIGATOR database.

Additional file 5. File $\mathbf{S 1}$. The list of 420 luminal samples obtained from UCSC Xena Browser and the Genomic Data Commons (GDC) database.

Additional file 6. File S2. The list of co-expressed genes with LINC01133, ZEB1-AS1 and ABHD11-AS1 across the selected luminal A and B BC samples.

Additional file 7. File S3. The list of biological process (BP), cellular component (CC), and molecular function (MF) categories, retrieved from DAVID database.

\section{Acknowledgements}

The authors would like to appreciate Ms. Marzie Samimifar for proofreading the English language of the manuscript, Ms. Narges Jafarbeik-Iravani and Dr. Rasoul Abdollahzadeh for valuable assistance during this project. We also thank other members of Genetics department of Breast Cancer Research Center of Motamed Cancer Institute, ACECR, Tehran, Iran. 


\section{Authors' contributions}

SM designed and performed bioinformatics analysis, conducted the experiments and wrote the manuscript. MA contributed to experiments and bioinformatics analysis, and revised the manuscript. AS designed the research strategy. MMN performed the statistical analysis. YM provided samples and clinical data. JTB and RE supervised the whole project, designed the research strategy, provided samples and clinical data and revised the manuscript. All authors read and approved the final manuscript.

\section{Funding}

This project was supported by the Faculty of Medicine, Tehran University of Medical Sciences (TUMS). Our tissue samples were obtained from Breast Cancer Research Center of Motamed Cancer Institute (Tehran, Iran).

\section{Availability of data and materials}

The datasets supporting the conclusions of this article are available in: [LnC2Cancer database] at (https://www.bio-bigdata.com/Inc2cancer/). [UCSC Xena browser] at (http://xena.ucsc.edu/); [GDC database] at (https://portal.gdc. cancer.gov/). [TANRIC database] at (https://www.tanric.org); [GENEVESTIGATOR database] at (https://genevestigator.com); [International Cancer Genome Consortium] at (https://dcc.icgc.org). [DAVID database] at (https://david.ncifc rf.gov). [REVIGO database] at (https://revigo.irb.hr). [Cytoscape software] at (https://www.cytoscape.org). [STRING database] at (https://string-db.org). [Enrichr database] at (https://maayanlab.cloud/Enrichr/). Citation of all data is provided in the references list. The datasets supporting the conclusions of this article are also included within the article and its additional files.

\section{Declarations}

\section{Ethics approval and consent to participate}

The Ethics committee of Tehran University of Medical Sciences (TUMS) has approved the present research (Code: IR.TUMS.MEDICINE.REC.1398.792).

\section{Consent for publication}

Not applicable.

\section{Competing interests}

The authors declare that there are no conflicts of interest.

\section{Author details}

${ }^{1}$ Department of Medical Genetics, School of Medicine, Tehran University of Medical Sciences, Tehran, Iran. ${ }^{2}$ Medical Genetic Ward, Imam Khomeini Hospital Complex, Tehran University of Medical Sciences, Tehran, Iran. ${ }^{3}$ Breast Disease Research Center (BDRC), Tehran University of Medical Sciences, Tehran, Iran. ${ }^{4}$ Noncommunicable Diseases Research Center, Fasa University of Medical Sciences, Fasa, Iran. ${ }^{5}$ Department of Medical Genetics, Fasa University of Medical Sciences, Fasa, Iran. ${ }^{6}$ Genetics Department, Breast Cancer Research Center, Motamed Cancer Institute, ACECR, Tehran, Iran.

\section{Received: 24 January 2021 Accepted: 5 August 2021}

Published online: 26 August 2021

\section{References}

1. Siegel RL, Miller KD, Jemal A. Cancer statistics, 2020. CA Cancer J Clin. 2020;70:7-30

2. Zaidi Z, Dib HA. The worldwide female breast cancer incidence and survival, 2018. AACR. 2019. https://doi.org/10.1158/1538-7445.AM2019-4191.

3. Bray F, Ferlay J, Soerjomataram I, Siegel RL, Torre LA, Jemal A. Global cancer statistics 2018: GLOBOCAN estimates of incidence and mortality worldwide for 36 cancers in 185 countries. CA Cancer J Clin. 2018;68:394-424.

4. Mathias C, Zambalde EP, Rask P, Gradia DF, de Oliveira JC. Long noncoding RNAs differential expression in breast cancer subtypes: what do we know? Clin Genet. 2019;95:558-68.

5. Makki J. Diversity of breast carcinoma: histological subtypes and clinical relevance. Clin Med Insights Pathol. 2015:8:CPath.S31563.
6. Abdel-Hafiz HA. Epigenetic mechanisms of tamoxifen resistance in luminal breast cancer. Diseases. 2017;5:16.

7. Yang F, Lv S-X, Lv L, Liu Y-H, Dong S-Y, Yao Z-H, Dai X-X, Zhang X-H, Wang O-C. Identification of IncRNA FAM83H-AS1 as a novel prognostic marker in luminal subtype breast cancer. OncoTargets Ther. 2016;9:7039.

8. Yang G, Shen T, Yi X, Zhang Z, Tang C, Wang L, Zhou Y, Zhou W. Crosstalk between long non-coding RNA $s$ and Wnt/ $\beta$-catenin signalling in cancer J Cell Mol Med. 2018;22:2062-70.

9. Wang KC, Chang HY. Molecular mechanisms of long noncoding RNAs. Mol Cell. 2011;43:904-14.

10. Zarkou V, Galaras A, Giakountis A, Hatzis P. Crosstalk mechanisms between the WNT signaling pathway and long non-coding RNAs. Noncoding RNA Res. 2018;3:42-53.

11. Sanchez Calle A, Kawamura Y, Yamamoto Y, Takeshita F, Ochiya T. Emerging roles of long non-coding RNA in cancer. Cancer Sci. 2018;109:2093-100.

12. Sahu A, Singhal U, Chinnaiyan AM. Long noncoding RNAs in cancer: from function to translation. Trends Cancer. 2015;1:93-109.

13. Chandra Gupta S, Nandan TY. Potential of long non-coding RNAs in cancer patients: from biomarkers to therapeutic targets. Int J Cancer. 2017;140:1955-67.

14. Yarmishyn AA, Kurochkin IV. Long noncoding RNAs: a potential novel class of cancer biomarkers. Front Genet. 2015;6:145.

15. Yang X-Z, Cheng T-T, He Q-J, Lei Z-Y, Chi J, Tang Z, Liao Q-X, Zhang H, Zeng L-S, Cui S-Z. LINC01133 as ceRNA inhibits gastric cancer progression by sponging miR-106a-3p to regulate APC expression and the Wnt/ $\beta$ catenin pathway. Mol Cancer. 2018:17:126

16. Liu M, Shen C, Wang C. Long noncoding RNA LINC01133 confers tumorsuppressive functions in ovarian cancer by regulating leucine-rich repeat kinase 2 as an miR-205 sponge. Am J Pathol. 2019;189:2323-39.

17. Yang X-Z, He Q-J, Cheng T-T, Chi J, Lei Z-Y, Tang Z, Liao Q-X, Zhang H, Zeng L-S, Cui S-Z. Predictive value of LINC01133 for unfavorable prognosis was impacted by alcohol in esophageal squamous cell carcinoma. Cell Physiol Biochem. 2018;48:251-62.

18. Zheng YF, Zhang XY, Bu YZ. LINC01133 aggravates the progression of hepatocellular carcinoma by activating the PI3K/AKT pathway. J Cell Biochem. 2019;120:4172-9.

19. Huang C-S, Chu J, Zhu X-X, Li J-H, Huang X-T, Cai J-P, Zhao W, Yin X-Y. The C/EBPß-LINC01133 axis promotes cell proliferation in pancreatic ductal adenocarcinoma through upregulation of CCNG1. Cancer Lett. 2018;421:63-72.

20. Zeng H-F, Qiu H-Y, Feng F-B. Long noncoding RNA LINC01133 functions as an miR-422a sponge to aggravate the tumorigenesis of human osteosarcoma. Oncol Res. 2018;26:335-43.

21. Ni X, Ding Y, Yuan H, Shao J, Yan Y, Guo R, Luan W, Xu M. Long non-coding RNA ZEB1-AS1 promotes colon adenocarcinoma malignant progression via miR-455-3p/PAK2 axis. Cell Prolif. 2020;53:e12723.

22. Zhang L-L, Zhang L-F, Guo X-H, Zhang D-Z, Yang F, Fan Y-Y. Downregulation of miR-335-5p by long noncoding RNA ZEB1-AS1 in gastric cancer promotes tumor proliferation and invasion. DNA Cell Biol. 2018;37:46-52.

23. Li T, Xie J, Shen C, Cheng D, Shi Y, Wu Z, Deng X, Chen H, Shen B, Peng C. Upregulation of long noncoding RNA ZEB1-AS1 promotes tumor metastasis and predicts poor prognosis in hepatocellular carcinoma. Oncogene. 2016:35:1575-84.

24. Lv Q-L, Hu L, Chen S-H, Sun B, Fu M-L, Qin C-Z, Qu Q, Wang G-H, He C-J, Zhou $\mathrm{H}-\mathrm{H}$. A long noncoding RNA ZEB1-AS1 promotes tumorigenesis and predicts poor prognosis in glioma. Int J Mol Sci. 2016;17:1431.

25. Wen J, Wang H, Dong T, Gan P, Fang H, Wu S, Li J, Zhang Y, Du R, Zhu Q. STAT3-induced upregulation of InCRNA ABHD11-AS1 promotes tumour progression in papillary thyroid carcinoma by regulating miR-1301-3p/ STAT3 axis and PI3K AKT signalling pathway. Cell Prolif. 2019;52:e12569.

26. Qiao X, Lv S, Qiao Y, Li Q, Ye B, Wang C, Miao L. Long noncoding RNA ABHD11-AS1 predicts the prognosis of pancreatic cancer patients and serves as a promoter by activating the PI3K-AKT pathway. Eur Rev Med Pharmacol Sci. 2018;22:8630-9.

27. Gao $Y$, Wang $P$, Wang $Y$, Ma X, Zhi H, Zhou D, Li X, Fang $Y$, Shen W, Xu Y. Lnc2Cancer v2.0: updated database of experimentally supported long non-coding RNAs in human cancers. Nucleic Acids Res. 2019;47:D1028-33.

28. Ning S, Zhang J, Wang P, Zhi H, Wang J, Liu Y, Gao Y, Guo M, Yue M, Wang L. Lnc2Cancer: a manually curated database of experimentally supported 
IncRNAs associated with various human cancers. Nucleic Acids Res. 2016;44:D980-5.

29. Majidzadeh-a K, Kaviani A, Esmaeili R, Farahmand L, Shojamoradi MH, Zare AA, Eini L, Abbasvandi F, Olfatbakhsh A, Moazen H. Iranian Breast Cancer Bio-Bank: the activity and challenging issues. Cell Tissue Bank. 2013;14:11-20.

30. Goldman MJ, Craft B, Hastie M, Repečka K, McDade F, Kamath A, Banerjee A, Luo Y, Rogers D, Brooks AN. Visualizing and interpreting cancer genomics data via the Xena platform. Nat Biotechnol. 2020:38:675-8.

31. Jensen MA, Ferretti V, Grossman RL, Staudt LM. The NCI Genomic Data Commons as an engine for precision medicine. Blood. 2017;130:453-9.

32. Li J, Han L, Roebuck P, Diao L, Liu L, Yuan Y, Weinstein JN, Liang H. TANRIC: an interactive open platform to explore the function of IncRNAs in cancer. Cancer Res. 2015;75:3728-37.

33. Hruz T, Laule O, Szabo G, Wessendorp F, Bleuler S, Oertle L, Widmayer $P$, Gruissem W, Zimmermann P. Genevestigator v3: a reference expression database for the meta-analysis of transcriptomes. Adv Bioinform. 2008. https://doi.org/10.1155/2008/420747.

34. Zhang J, Baran J, Cros A, Guberman JM, Haider S, Hsu J, Liang Y, Rivkin E, Wang J, Whitty B. International Cancer Genome Consortium Data Portal —a one-stop shop for cancer genomics data. Database. 2011. https://doi.org/10.1093/database/bar026.

35. Huang DW, Sherman BT, Lempicki RA. Bioinformatics enrichment tools: paths toward the comprehensive functional analysis of large gene lists. Nucleic Acids Res. 2009;37:1-13.

36. Sherman BT, Lempicki RA. Systematic and integrative analysis of large gene lists using DAVID bioinformatics resources. Nat Protoc. 2009;4:44

37. Supek F, Bošnjak M, Škunca N, Šmuc T. REVIGO summarizes and visualizes long lists of gene ontology terms. PLoS ONE. 2011;6:e21800.

38. Shannon P, Markiel A, Ozier O, Baliga NS, Wang JT, Ramage D, Amin N, Schwikowski B, Ideker T. Cytoscape: a software environment for integrated models of biomolecular interaction networks. Genome Res. 2003;13:2498-504.

39. Chin C-H, Chen S-H, Wu H-H, Ho C-W, Ko M-T, Lin C-Y. cytoHubba: identifying hub objects and sub-networks from complex interactome. BMC Syst Biol. 2014;8:S11.

40. Szklarczyk D, Gable AL, Lyon D, Junge A, Wyder S, Huerta-Cepas J, Simonovic M, Doncheva NT, Morris JH, Bork P. STRING v11: protein-protein association networks with increased coverage, supporting functional discovery in genome-wide experimental datasets. Nucleic Acids Res. 2019:47:D607-13.

41. Kuleshov MV, Jones MR, Rouillard AD, Fernandez NF, Duan Q, Wang Z, Koplev S, Jenkins SL, Jagodnik KM, Lachmann A. Enrichr: a comprehensive gene set enrichment analysis web server 2016 update. Nucleic Acids Res. 2016:44:W90-7.

42. Ou J, Zhu LJ. trackViewer: a Bioconductor package for interactive and integrative visualization of multi-omics data. Nat Methods. 2019;16:453-4.

43. Chen X, Cong Y, Pan L, Jiang Y, Meng Q, Sun L, Pang H, Zhao Y, Dong X, Cai L. Luminal (Her2 negative) prognostic index and survival of breast cancer patients. Cancer Epidemiol. 2014;38:286-90.

44. Cheang MC, Chia SK, Voduc D, Gao D, Leung S, Snider J, Watson M, Davies S, Bernard PS, Parker JS. Ki67 index, HER2 status, and prognosis of patients with luminal B breast cancer. JNCI. 2009;101:736-50.
45. Kornienko AE, Dotter CP, Guenzl PM, Gisslinger H, Gisslinger B, Cleary C, Kralovics R, Pauler FM, Barlow DP. Long non-coding RNAs display higher natural expression variation than protein-coding genes in healthy humans. Genome Biol. 2016;17:14.

46. Song Z, Zhang X, Lin Y, Wei Y, Liang S, Dong C. LINC01133 inhibits breast cancer invasion and metastasis by negatively regulating $\mathrm{SOX} 4$ expression through EZH2. J Cell Mol Med. 2019:23:7554-65.

47. Luo N, Zhang K, Li X, Hu Y. ZEB1 induced-upregulation of long noncoding RNA ZEB1-AS1 facilitates the progression of triple negative breast cancer by binding with ELAVL1 to maintain the stability of ZEB1 mRNA. J Cell Biochem. 2020;121(10):4176-87.

48. Ponting CP, Oliver PL, Reik W. Evolution and functions of long noncoding RNAs. Cell. 2009:136:629-41.

49. Minotti L, Agnoletto C, Baldassari F, Corrà F, Volinia S. SNPs and somatic mutation on long non-coding RNA: new frontier in the cancer studies? High-throughput. 2018;7:34.

50. He F, Wei R, Zhou Z, Huang L, Wang Y, Tang J, Zou Y, Shi L, Gu X, Davis M. Integrative analysis of somatic mutations in non-coding regions altering RNA secondary structures in cancer genomes. Sci Rep. 2019;9:1-12.

51. Perron U, Provero P, Molineris I. In silico prediction of IncRNA function using tissue specific and evolutionary conserved expression. BMC Bioinform. 2017;18:144.

52. Wong DC, Sweetman C, Ford CM. Annotation of gene function in citrus using gene expression information and co-expression networks. BMC Plant Biol. 2014;14:186.

53. Brockhausen I. Mucin-type O-glycans in human colon and breast cancer: glycodynamics and functions. EMBO Rep. 2006;7:599-604.

54. Cheng HS, Lee JXT, Wahli W, Tan NS. Exploiting vulnerabilities of cancer by targeting nuclear receptors of stromal cells in tumor microenvironment. Mol Cancer. 2019;18:51.

55. Doan TB, Graham JD, Clarke CL. Emerging functional roles of nuclear receptors in breast cancer. J Mol Endocrinol. 2017;58:R169-90.

56. Zhang HS, Zhang ZG, Du GY, Sun HL, Liu HY, Zhou Z, Gou XM, Wu XH, Yu $X Y$, Huang YH. Nrf2 promotes breast cancer cell migration via up-regulation of G6PD/HIF-1a/Notch1 axis. J Cell Mol Med. 2019;23:3451-63.

57. Capper CP, Rae JM, Auchus R. The metabolism, analysis, and targeting of steroid hormones in breast and prostate cancer. Horm Cancer. 2016:7:149-64.

58. Brennan K, Offiah G, McSherry EA, Hopkins AM. Tight junctions: a barrier to the initiation and progression of breast cancer? J Biomed Biotechnol. 2010. https://doi.org/10.1155/2010/46060.

59. Khramtsov Al, Khramtsova GF, Tretiakova M, Huo D, Olopade Ol, Goss KH. $\mathrm{Wnt} / \mathrm{\beta}$-catenin pathway activation is enriched in basal-like breast cancers and predicts poor outcome. Am J Pathol. 2010;176:2911-20.

60. Katoh M, Nakagama H. FGF receptors: cancer biology and therapeutics. Med Res Rev. 2014;34:280-300.

\section{Publisher's Note}

Springer Nature remains neutral with regard to jurisdictional claims in published maps and institutional affiliations.

Ready to submit your research? Choose BMC and benefit from

- fast, convenient online submission

- thorough peer review by experienced researchers in your field

- rapid publication on acceptance

- support for research data, including large and complex data types

- gold Open Access which fosters wider collaboration and increased citations

- maximum visibility for your research: over $100 \mathrm{M}$ website views per year

At BMC, research is always in progress.

Learn more biomedcentral.com/submissions 